\title{
Contribution of Estrogen to Sex Dimorphic Expression of Cardiac Natriuretic Peptide and Nitric Oxide Synthase Systems in ANP Gene-Disrupted Mice
}

\author{
Philip G. Wong, David W. J. Armstrong, M. Yat Tse, Nicole M. Ventura, Stephen C. Pang* \\ Department of Biomedical and Molecular Sciences, Queen's University, Kingston, Canada \\ Email: *pangsc@queensu.ca
}

Received May 29, 2013; revised June 29, 2013; accepted July 23, 2013

Copyright (C) 2013 Philip G. Wong et al. This is an open access article distributed under the Creative Commons Attribution License, which permits unrestricted use, distribution, and reproduction in any medium, provided the original work is properly cited.

\begin{abstract}
Background: Sex dimorphism in the prevalence, onset, development and progression of cardiovascular disease (CVD) is well recognized, but the mechanisms whereby sex hormones which are believed to confer cardioprotection are still not fully understood. Objective: This study more closely delineates the effect of $17 \beta$-Estradiol (E2) on the expression and signaling of the cardiac NP and NOS systems, well-known cardioprotective modulators of the cardiac hypertrophy $(\mathrm{CH})$ response, that both contribute to downstream production of cyclic guanosine 3',5'-monophosphate (cGMP). Materials and Methods: Ovariectomized (OVX) female $\mathrm{ANP}^{+/+}$and $\mathrm{ANP}^{-/-}$mice, 6 - 7 weeks old, were subjected to a five-week treatment with E2 (100 $\mu \mathrm{g} / 100 \mu \mathrm{L} /$ day) or vehicle (VEH). Left ventricle from these treatment groups, along with that from age-matched male $\mathrm{ANP}^{+/+}$and $\mathrm{ANP}^{-/}$mice was used to assess expression of these systems by real-time quantitative PCR (qPCR). Left ventricle tissue and plasma cGMP were measured by enzyme immunoassay to assess alterations in resultant downstream signaling. Results: NP system expression was unchanged across genotype, sex and E2 treatment. Sex-specific differences in NOS system expression were observed; female mice showed an increased expression of NOS system genes that were significantly elevated in all but one of the E2 treatment groups. Left ventricle tissue cGMP remained unchanged across genotype, sex and E2 treatment. Plasma cGMP levels were unchanged in $\mathrm{ANP}^{+/+}$treatment groups. In $\mathrm{ANP}^{-/-}$treatment groups, plasma cGMP in the female OVX-E2 mice was significantly higher compared to male and female OVX-VEH mice. Conclusion: These findings demonstrate that in the absence of ANP, E2 upregulates cardiac NOS system expression to produce cGMP. This study confirms the importance of the cardiac NOS system in females; this particular system may be a promising future target for sex-specific treatments and therapies for CVD in women.
\end{abstract}

Keywords: Estrogen; Atrial Natriuretic Peptide; Nitric Oxide Synthase; Sex Dimorphism; Heart

\section{Introduction}

Cardiovascular disease (CVD) is a leading cause of morbidity and mortality in the Western population; the past decade has seen a decline in the rate of CVD related deaths, but the burden of CVD continues to remain high [1]. CVD-related mortality in older women is higher than in older men; the contribution of sex hormone depletion in menopause to the development of CVD remains controversial [2]. Nevertheless, the dichotomy in sex-specific clinical CVD-related outcomes warrants further and more complete investigation into sex-specific mechanisms that presumably confer cardioprotection.

The development of cardiac hypertrophy $(\mathrm{CH})$ is well

"Corresponding author. established as a primary independent risk factor for, and indicator of future development of hypertension and associated CVD [3]. CH is a maladaptive increase in cardiac mass that occurs as a consequence of a re-induction of fetal cardiac gene programs, promoting cardiac adaptation to pathological stimuli [4]. The natriuretic peptide (NP) and nitric oxide synthase (NOS) systems are considered to be cardioprotective, and responsible for the modulation of the $\mathrm{CH}$ response through convergent downstream production of cyclic guanosine 3',5'-mono-phosphate (cGMP), a secondary messenger that activates protein kinase $\mathrm{G}(\mathrm{PKG})$ which is responsible for the further regulation of downstream gene systems that contribute to maintenance and regulation of cardiomyocyte growth, and modulation of cardiac remodeling [5-7]. 
Recently, we presented evidence of the existence of sex-specific differences in the expression of the cardiac NP and NOS systems in ANP gene-disrupted mice $\left(\mathrm{ANP}^{-/-}\right)$, documenting how each sex utilizes a different system to conserve downstream cGMP production [8]. Interestingly, changes in NOS system expression were found to mirror the cyclical changes of the estrous cycle. As an extension to these findings, the current study was undertaken to determine and confirm if this female-specific estrous cycle-mediated alteration in cardiac gene expression is sex hormone mediated, and specifically attributable to estrogen. In this study, we explored the direct impact of $17 \beta$-Estradiol (E2) on the expression and signaling of the cardiac NP and NOS systems in ovariectomized (OVX) female $\mathrm{ANP}^{+/+}$and $\mathrm{ANP}^{-/-}$mice subjected to a five-week treatment of either E2 or vehicle (VEH), compared to age matched male $\mathrm{ANP}^{+/+}$and $\mathrm{ANP}^{--}$mice.

It is well accepted that the NP and NOS systems can exert effects, both systematically and targeted to individual organs. In this study, we will focus on the organspecific effects of these systems. Specifically, we will focus this study on the estrogenic influence on gene systems that are directly implicated in the modulation of the cardiac hypertrophic response. Presently, the use of hormone replacement therapy (HRT) has received close scrutiny with regard to its efficacy and associated spectrum of risks and benefits. A deeper understanding of the role of sex hormones in female-specific cardiac protection is warranted [9]. Deciphering the intricacies of sex hormone influence on the heart will add to our understanding of female-specific mechanisms of cardioprotection, supplement existing research pertaining to the use and implementation of HRT, and further contribute to future development of sex-specific targeted therapies and treatments for CVD in women.

\section{Materials and Methods}

\subsection{Experimental Animals}

$\mathrm{ANP}^{+/+}$and $\mathrm{ANP}^{-/-}$mice were bred and maintained by Animal Care Services at Queen's University, Kingston, Ontario, Canada. This mouse colony was established from breeding pairs originating from the laboratory of Oliver Smithies, and has been maintained at Queen's University since 1995. Mice were housed in plastic cages (maximum of four animals per cage), maintained at room temperature $\left(21^{\circ} \mathrm{C} \pm 1{ }^{\circ} \mathrm{C}\right)$ on a 12-hour light: 12-hour dark schedule, and allowed access to normal mouse chow and tap water ad libitum. Experimental animal protocols were approved by the Animal Care Committee at Queen's University in accordance with the Canadian Council on Animal Care. Genotyping of mice was accomplished using a tail sample retrieved at 3 weeks of age and processed using a previously published PCRbased method [10].

\subsection{Ovariectomy}

Female $\mathrm{ANP}^{+/+}$and $\mathrm{ANP}^{-/-}$mice, 6 - 7 weeks of age, were ovariectomized (OVX) using sterile technique. Briefly, each mouse was anesthetized by isoflurane, the dorsum shaved, and a single midline incision was made. Subcutaneous spaces on either side of the incision were made by blunt dissection. Bilateral access to the abdomen was achieved through two small incisions in the posterior abdominal wall. Ovaries were exteriorized, removed using sharp scissors and the intact uterine horns returned to the abdomen. The midline skin incision was closed and secured by two removable metal staples. Bupivacaine (one dose post-surgery, $1 \mathrm{mg} / \mathrm{kg}$ body weight) and Metacam (two doses, one dose post-surgery and the second 24 hours post-surgery, $1 \mathrm{mg} / \mathrm{kg}$ body weight) were administered for post-operative pain management.

\subsection{7 $\beta$-Estradiol (E2) Administration}

Administration of E2 commenced 1 - 2 weeks post-OVX. E2 was dissolved in ethanol and diluted in sterilized corn oil. Subcutaneous E2 injections delivered $100 \mu \mathrm{g} / 100 \mu \mathrm{L}$ daily over a five-week period. This dose was based upon previously published work from our lab documenting the cardioprotective effects of $\mathrm{E} 2$ in $\mathrm{ANP}^{-/-}$mice treated with high dietary salt $[11,12]$.

\subsection{Plasma and Tissue Collection}

Collection of plasma and cardiac tissues was accomplished by a previously published method [8]. Briefly, mice were anesthetized using Somnotol $(100 \mathrm{mg} / \mathrm{kg}$ body weight). Blood was collected by cardiac puncture and added to tubes containing aprotinin $(1000 \mathrm{KIU} / \mathrm{mL})$ and disodium ethylenediaminetetraacetic acid (EDTA, 2 $\mu \mathrm{mol} / \mathrm{mL}$ ). Blood samples were centrifuged at $8000 \times \mathrm{g}$ for 10 minutes and the retrieved plasma was stored at $-80^{\circ} \mathrm{C}$. Following blood collection, the heart was harvested and dissected, separating left and right atria, left ventricle (including ventricular septum) and right ventricle. Heart chambers were weighed, divided into smaller pieces (approximately $25 \mathrm{mg}$ each), then snap frozen in liquid nitrogen and stored at $-80^{\circ} \mathrm{C}$.

\subsection{7 $\beta$-Estradiol (E2) Enzyme Immunoassay}

Plasma levels of E2 were assessed to confirm successful administration of E2 in experimental animals using an E2 EIA (item no: 582251, Cayman Chemical Company, Ann Arbor, MI, USA). Undiluted plasma samples were assayed directly. Background activity was determined by 
stripping control plasma samples with dextran coated Norit A charcoal (Cat. No.: AC40403-5000 Fisher Scientific, Ottawa, Ontario, Canada). The detection limit for this assay is $19 \mathrm{pg} / \mathrm{mL}$.

\subsection{Isolation of RNA and Generation of cDNA by Reverse Transcription}

Left ventricle tissue RNA was isolated by a modified Trizol method utilizing a high pure RNA tissue isolation kit (Cat. No. 11828665001, Roche Scientific Co., Laval, QC, Canada). Subsequent reverse transcription of RNA to cDNA was accomplished using a high-capacity cDNA reverse transcription kit (Applied Biosystems, Streetsville, ON, Canada). Protocols were performed according to manufacturer's instructions; further experimental protocol details were previously published [8].

\subsection{Real-Time Quantitative PCR}

Analysis of expression of the NP and NOS systems was determined relative to GAPDH mRNA using qPCR (Roche LightCycler 480 II System, Laval, QC, Canada). Roche LightCycler 480 II internal software was used to determine relative quantification of gene levels by plotting crossing point $(\mathrm{Cp})$ values against standard curves derived from each specific primer set. Primer sets were designed using Primer Designer version 2.01 (Scientific and Educational Software, Cary, Indiana, USA) in accordance with published GenBank sequences (http://www.ncbi.nlm.nih.gov/Genbank). Conventional PCR was used to confirm that these primer sets amplified a single amplicon of the correct size. These primer sets along with their respective annealing temperatures and standard curve efficiencies are listed in Table 1. Only primer sets yielding efficiencies within a range of 1.9 2.1 were used.

\subsection{Cyclic GMP Enzyme Immunoassay}

Left ventricle tissue and plasma levels of cGMP were measured using a cGMP enzyme immunoassay (EIA) kit (Item No.: 581021, Cayman Chemical Company, AnnArbor, MI, USA). The detection limit for this assay is 0.1 $\mathrm{pmol} / \mathrm{mL}$. The immunoassay was carried out according to the manufacturer's instructions; further details pertaining to the cGMP extraction from both left ventricle tissue and plasma were previously published [8].

\subsection{Data and Statistical Analysis}

Left ventricle tissue weight to body weight ratios of male, female OVX-VEH and female OVX-E2 $\mathrm{ANP}^{+/+}$and $\mathrm{ANP}^{-/-}$mice were compared using 2-way ANOVA with

Table 1. Real-time qPCR primer sets, annealing temperatures $\left(T_{a}\right)$ and standard curve efficiency values for the NP and NOS system genes assessed.

\begin{tabular}{|c|c|c|c|c|c|}
\hline & GENE & \multicolumn{2}{|c|}{ SEQUENCE } & $\begin{array}{l}\text { ANNEALING } \\
\text { TEMPERATURES }\left(\mathrm{T}_{\mathrm{a}}\right)\end{array}$ & $\begin{array}{l}\text { STANDARD CURVE } \\
\text { EFFICIENCY }\end{array}$ \\
\hline \multirow{6}{*}{ 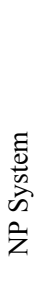 } & \multirow{2}{*}{ ANP } & S & CAAGAACCTGCTAGACCACC & $62^{\circ} \mathrm{C}$ & \multirow{2}{*}{2.036} \\
\hline & & AS & AGCTGTTGCAGCCTAGTCC & $63^{\circ} \mathrm{C}$ & \\
\hline & \multirow{2}{*}{ BNP } & S & CCAGAGACAGCTCTTGAAGG & $63^{\circ} \mathrm{C}$ & \multirow{2}{*}{2.026} \\
\hline & & AS & TCCGATCCGGTCTATCTTG & $63^{\circ} \mathrm{C}$ & \\
\hline & \multirow{2}{*}{ NPR-A } & S & CCAGCATCCTTCCATGAC & $61^{\circ} \mathrm{C}$ & \multirow{2}{*}{2.047} \\
\hline & & AS & GTTCCACATCCGCTGAGT & $61^{\circ} \mathrm{C}$ & \\
\hline & \multirow{2}{*}{ NPR-C } & $\mathrm{S}$ & CAGCAGACTTGGAACAGGA & $62^{\circ} \mathrm{C}$ & \multirow{2}{*}{2.079} \\
\hline & & AS & CCATTAGCAAGCCAGCAC & $62^{\circ} \mathrm{C}$ & \\
\hline & \multirow{2}{*}{ iNOS } & $\mathrm{S}$ & CCAGGCTGGAAGCTGTAAC & $63^{\circ} \mathrm{C}$ & \multirow{2}{*}{2.003} \\
\hline & & AS & AGTGATGGCCGACCTGAT & $63^{\circ} \mathrm{C}$ & \\
\hline \multirow{8}{*}{ 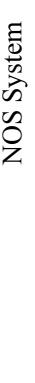 } & \multirow{2}{*}{ eNOS } & $\mathrm{S}$ & TTGAGGATGTGGCTGTGTG & $63^{\circ} \mathrm{C}$ & \multirow{2}{*}{1.988} \\
\hline & & AS & GAGTTAGGCTGCCTGAGATG & $63^{\circ} \mathrm{C}$ & \\
\hline & \multirow{2}{*}{$\mathrm{sGC} \alpha_{1}$} & $\mathrm{~S}$ & TGTGATCGCATCATGGTG & $61^{\circ} \mathrm{C}$ & \multirow{2}{*}{2.089} \\
\hline & & AS & CTCTGTTGGCTCCTTAGGAA & $62^{\circ} \mathrm{C}$ & \\
\hline & \multirow{2}{*}{$\mathrm{sGC} \beta_{1}$} & $\mathrm{~S}$ & TTCGTCTTCTGCCAGGAGT & $63^{\circ} \mathrm{C}$ & \multirow{2}{*}{2.087} \\
\hline & & AS & CCGAGTAGTAGTGCAGGATGA & $63^{\circ} \mathrm{C}$ & \\
\hline & \multirow{2}{*}{ GAPDH } & S & TGACTCCACTCACGGCAA & $63^{\circ} \mathrm{C}$ & \multirow{2}{*}{1.909} \\
\hline & & AS & ACTCCACGACATACTCAGCAC & $63^{\circ} \mathrm{C}$ & \\
\hline
\end{tabular}

Sense (S, forward direction), Anti-Sense (AS, reverse direction). 
Bonferroni's post hoc test. Within each genotype, plasma E2 levels were compared in female OVX-VEH and female OVX-E2 treatment groups using unpaired Student's $t$ test. All mRNA gene expression data using qPCR and assessment of cGMP levels in both left ventricle tissue and plasma were compared using one-way ANOVA with Tukey's post hoc test. Data were plotted and statistical analysis was performed using Graph Pad Prism 6 software (La Jolla, CA, USA). Other than stated, all data are presented as means \pm SEM. $\mathrm{P} \leq 0.05$ was considered statistically significant.

\section{Results}

\subsection{Cardiac Mass and Body Weight for Male, Female OVX-VEH and Female OVX-E2 $\mathbf{A N P}^{+/+}$and $\mathbf{A N P}^{-/-}$Mice}

Table 2 presents a summary of the cardiac mass and body weight for male, female OVX-VEH and female OVX-E2 $\mathrm{ANP}^{+/+}$and $\mathrm{ANP}^{-/-}$mice. Left ventricle tissue weight to body weight ratios (LVW/BW), rather than whole heart weight to body weight ratios were used because changes in left ventricle mass are a more accurate indicator of cardiac mass changes associated with hypertension development. Male, female OVX-VEH and female OVX-E2 $\mathrm{ANP}^{-/-}$mice exhibited significantly larger $\mathrm{LVW} / \mathrm{BW}$ ratios compared to their respective $\mathrm{ANP}^{+/+}$ counterparts. Male $\mathrm{ANP}^{-/-}$mice had a significant increase of $31 \%$ compared to male $\mathrm{ANP}^{+/+}$mice. Female $\mathrm{OVX}-\mathrm{VEH}$ treated $\mathrm{ANP}^{-/-}$mice had a significant increase of $41 \%$ compared to female OVX-VEH treated $\mathrm{ANP}^{+/+}$mice. Female OVX-E2 treated $\mathrm{ANP}^{-/-}$mice had a significant increase of $38 \%$ compared to female OVX$\mathrm{E} 2$ treated $\mathrm{ANP}^{+/+}$mice.

\subsection{Delivery of 17 $\beta$-Estradiol in Female OVX $\mathbf{A N P}^{+/+}$and $\mathbf{A N P}^{-/-}$Mice}

Levels of plasma E2 detected in female OVX-VEH and female OVX-E2 $\mathrm{ANP}^{+/+}$and $\mathrm{ANP}^{-/-}$mice are shown in Table 2. Female OVX-E2 $\mathrm{ANP}^{+/+}$and $\mathrm{ANP}^{-/-}$mice had significantly higher plasma E2 levels than their respective genotype female OVX-VEH counterparts. Plasma E2 levels were more prominently elevated in the female OVX-E2 $\mathrm{ANP}^{+/+}$mice compared to the female OVX-E2 $\mathrm{ANP}^{-/-}$mice.

\subsection{Cardiac Natriuretic Peptide System}

Expression of ANP and BNP, and their associated receptors NPR-A and NPR-C (clearance receptor) is shown in Figure 1. Expression of ANP in male $\mathrm{ANP}^{+/+}$mice was higher than female OVX-VEH and female OVX-E2 $\mathrm{ANP}^{+/+}$mice, but this increase did not reach statistical significance. There was no significant difference in the expression of BNP, NPR-A and NPR-C across genotype, gender, or treatment with E2.

\subsection{Cardiac Nitric Oxide Synthase System}

The mRNA expression of iNOS, eNOS, sGC $\alpha_{1}$ and ${ }_{\mathrm{sGC}} \beta_{1}$ is shown in Figure 2. In both genotypes, there was a trend towards increased expression of NOS system counterparts in female OVX-VEH mice compared to males of the same respective genotypes. The trend continues with female OVX-E2 mice demonstrating increased expression of NOS system counterparts compared to female OVX-VEH mice of the same respective genotypes. Expression of iNOS in female OVX-VEH $\mathrm{ANP}^{-/-}$mice was significantly higher compared to male $\mathrm{ANP}^{-/-}$mice. Female OVX-VEH $\mathrm{ANP}^{-/-}$mice had significantly higher levels of iNOS compared to female OVX-E2 ANP $^{-/}$mice. In both genotypes, expression of eNOS was significantly higher in the female OVX-VEH treated mice compared to males. As well, in both genotypes, with the exception of iNOS expression in the $\mathrm{ANP}^{+/+}$mouse treatment groups, levels of iNOS, eNOS, sGC $\alpha_{1}$ and $\mathrm{sGC} \beta_{1}$ expression were found to be signifi-

Table 2. Plasma 17 $\beta$-Estradiol (E2) levels and cardiac mass data for male, female OVX-VEH and female OVX-E2 ANP ${ }^{+/+}$and $\mathbf{A N P}^{-/-}$mice.

\begin{tabular}{cccccccc}
\hline GENDER & GENOTYPE & TREATMENT & E2 $(\mathrm{pg} / \mathrm{mL})$ & $\mathrm{n}$ & LVW $(\mathrm{mg})$ & BW $(\mathrm{g})$ & LVW/BW $(\mathrm{mg} / \mathrm{g})$ \\
\hline \multirow{2}{*}{ Male } & $\mathrm{ANP}^{+/+}$ & $\mathrm{n} / \mathrm{a}$ & $\mathrm{n} / \mathrm{a}$ & 4 & $77.3 \pm 4.1$ & $23.8 \pm 0.9$ & $3.2 \pm 0.1$ \\
& $\mathrm{ANP}^{-/-}$ & $\mathrm{n} / \mathrm{a}$ & $\mathrm{n} / \mathrm{a}$ & 4 & $123.1 \pm 9.5$ & $29.5 \pm 0.5$ & $4.2 \pm 0.4^{* *}$ \\
& $\mathrm{ANP}^{+/+}$ & OVX-VEH & $5.6 \pm 1.7$ & 5 & $65.3 \pm 3.2$ & $24.8 \pm 0.6$ & $2.7 \pm 0.2$ \\
\multirow{2}{*}{ Female } & $\mathrm{ANP}^{-/-}$ & OVX-VEH & $3.2 \pm 1.5$ & 5 & $91.2 \pm 3.6$ & $24.1 \pm 0.5$ & $3.8 \pm 0.1^{* *}$ \\
& $\mathrm{ANP}^{+/+}$ & OVX-E2 & $50.3 \pm 9.5^{*}$ & 5 & $69.5 \pm 3.6$ & $24.0 \pm 1.0$ & $2.9 \pm 0.1$ \\
& $\mathrm{ANP}^{-/-}$ & OVX-E2 & $19.5 \pm 2.5^{*}$ & 6 & $105.5 \pm 7.2$ & $26.1 \pm 0.6$ & $4.0 \pm 0.2^{* *}$ \\
\hline
\end{tabular}

Plasma E2 data are presented as means \pm S.E.M. ${ }^{*} \mathrm{P} \leq 0.05$ compared to OVX-VEH of the same respective genotype, using unpaired Student's $\mathrm{t}$ test. $\mathrm{N}=4-5$ Cardiac mass data are presented as mean $\pm \mathrm{SD} .{ }^{* *} \mathrm{P} \leq 0.05$ compared to $\mathrm{ANP}+/+$ genotype in males, and compared to $\mathrm{ANP}{ }^{+/+}$genotype and treatment $(\mathrm{VEH}$ or $\mathrm{E} 2)$ in females, using 2-way ANOVA and Bonferroni's post hoc test. $\mathrm{N}=4-6$. 


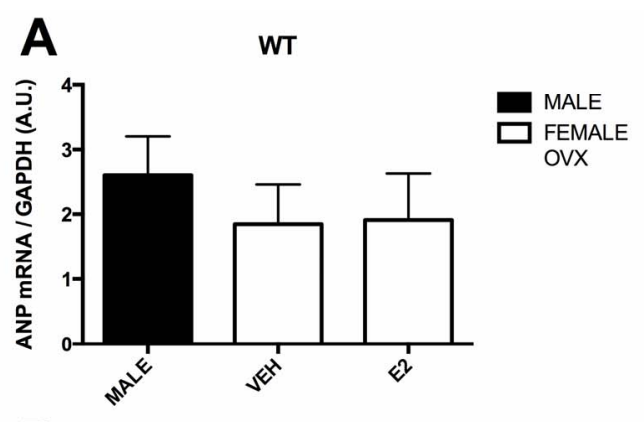

B

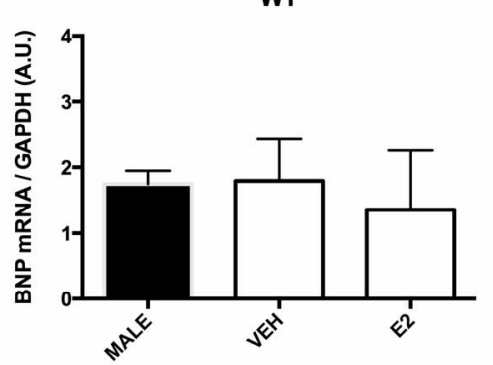

WT
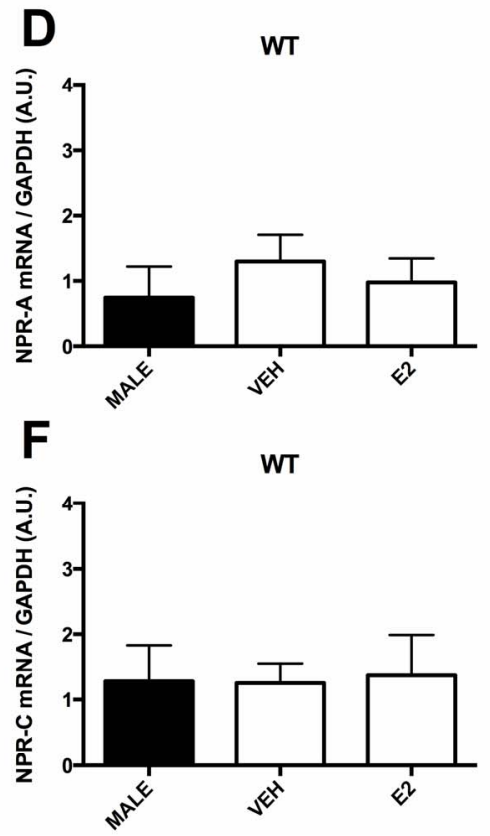

C ко

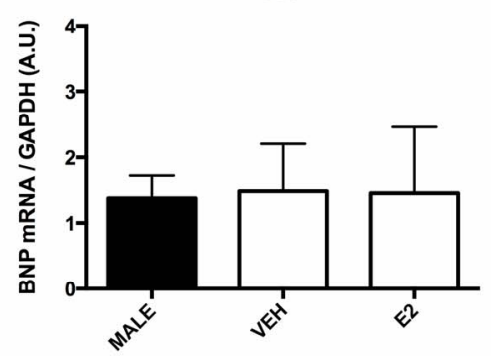

E ко

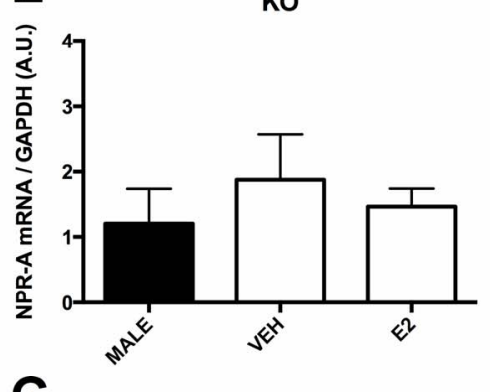

KO

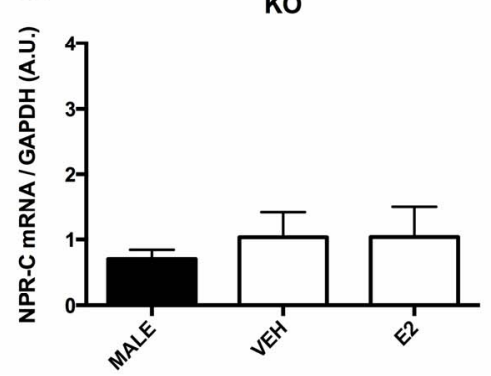

Figure 1. NP System Gene Expression-ANP mRNA expression in male, female OVX-VEH and female OVX-E2 ANP ${ }^{+/+}$mice (A); BNP mRNA expression in male, female OVX-VEH and female OVX-E2 ANP ${ }^{+/+}$mice (B), BNP mRNA expression in male, female OVX-VEH and female OVX-E2 $\mathrm{ANP}^{-/-}$mice (C); NPR-A expression in male, female OVX-VEH and female OVX-E2 $\mathrm{ANP}^{+/+}$mice (D), NPR-A mRNA expression in male, female OVX-VEH and female OVX-E2 ANP ${ }^{-/-}$mice (E); NPR-C expression in male, female OVX-VEH and female OVX-E2 ANP $^{+/+}$mice (F), NPR-C mRNA expression in male, female OVX-VEH and female OVX-E2 $\mathrm{ANP}^{-/-}$mice (G); Data are presented as means \pm S.E.M. * $\mathrm{P} \leq \mathbf{0 . 0 5}$, using one-way ANOVA and Tukey's post hoc test. $\mathrm{N}=4$ - 6 .

cantly higher in female OVX-E2 treated mice compared to their respective male $\mathrm{ANP}^{+/+}$and $\mathrm{ANP}^{-/-}$mouse treatment groups.

\subsection{Cyclic GMP Enzyme Immunoassay}

Figure 3 shows the results of measurement of cGMP levels found in left ventricle tissue and plasma in male, female OVX-VEH and female OVX-E2 $\mathrm{ANP}^{+++}$and $\mathrm{ANP}^{-/-}$mice. In both $\mathrm{ANP}^{+/+}$and $\mathrm{ANP}^{-/-}$mice, there was no significant difference in left ventricle cGMP levels regardless of sex or treatment. In $\mathrm{ANP}^{+/+}$mice, there was no significant difference in plasma cGMP levels between male, female OVX-VEH and female OVX-E2 mice. In 

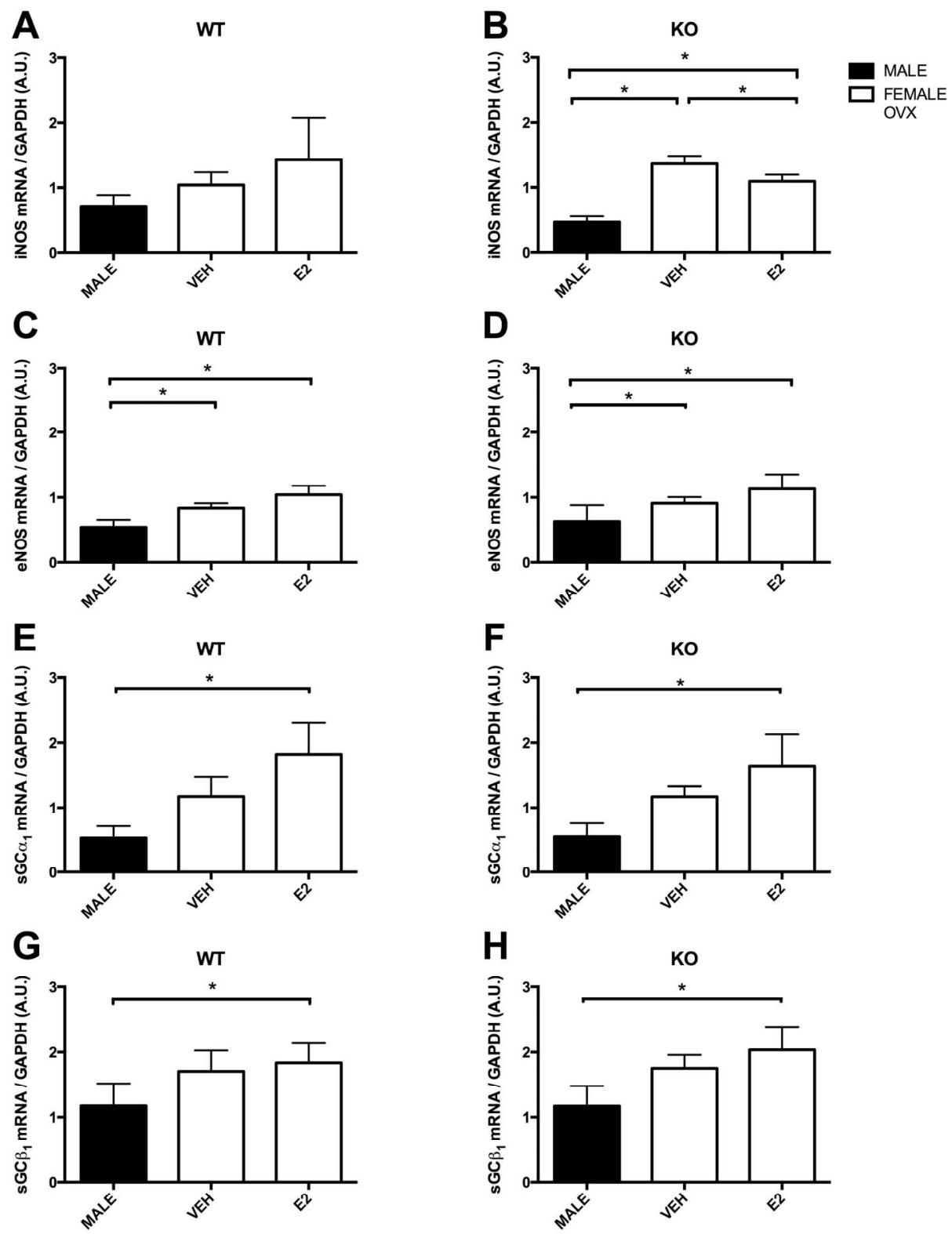

Figure 2. NOS System Gene Expression-iNOS mRNA expression in male, female OVX-VEH and female OVX-E2 ANP ${ }^{+/+}$ mice (A); iNOS mRNA expression in male, female OVX-VEH and female OVX-E2 $\mathrm{ANP}^{-/-}$mice (B); eNOS mRNA expression in male, female OVX-VEH and female OVX-E2 $\mathrm{ANP}^{+/+}$mice (C); eNOS mRNA expression in male, female OVX-VEH and

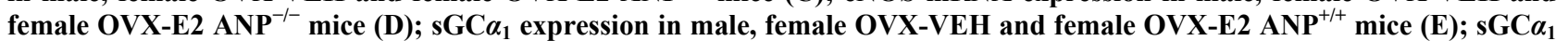
mRNA expression in male, female OVX-VEH and female OVX-E2 $\mathrm{ANP}^{-/-}$mice (F); sGC $\beta_{1}$ expression in male, female OVXVEH and female OVX-E2 $\mathrm{ANP}^{+/+}$mice (G), sGC $\beta_{1}$ mRNA expression in male, female OVX-VEH and female OVX-E2 ANP ${ }^{-/-}$ mice $(\mathrm{H})$; Data are presented as means \pm S.E.M. ${ }^{\mathrm{P}} \leq \mathbf{0 . 0 5}$, using one-way ANOVA and Tukey's post hoc test. $N=3-4$.

$\mathrm{ANP}^{-/-}$mice, female OVX-E2 mice had significantly higher levels of plasma cGMP compared to male and female OVX-VEH mice.

\section{Discussion}

While it is acknowledged and accepted that males and females are different, particularly in the prevalence, onset and development of risk factors that lead to CVD, this recognition has been slow to translate into both clinical and basic science research practice. Regardless of sex, women continue to be administered the same therapeutics as men, weight-adjusted for use by females. As well, the predominance of male-only studies in basic science research continues to be a widespread limitation to experimental scope, design and applicability. Sex is an important factor in the modulation of the progression of 

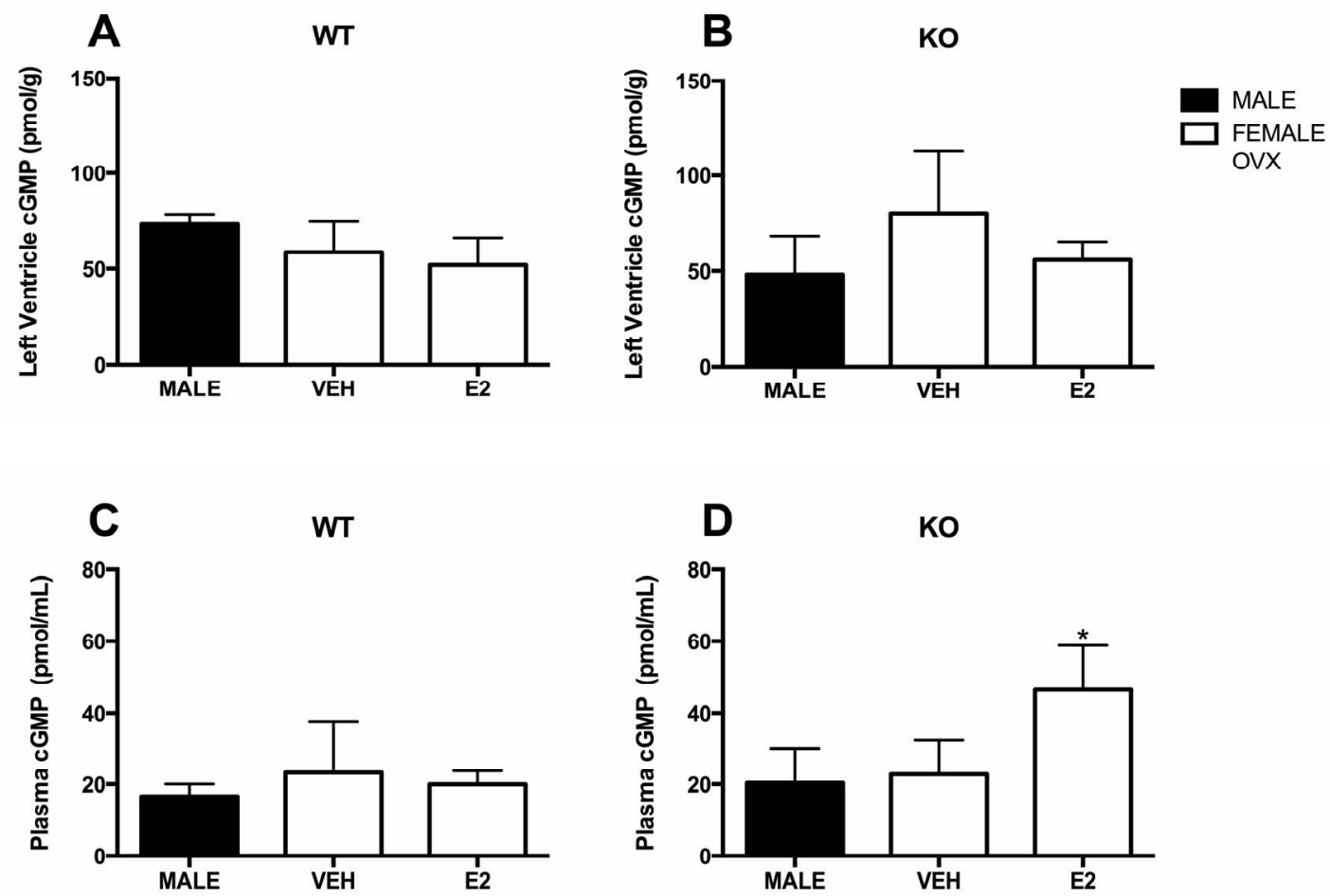

Figure 3. Left ventricle tissue cGMP (pmol/g) in male, female OVX-VEH and female OVX-E2 ANP ${ }^{+/+}$mice (A) and in male, female OVX-VEH and female OVX-E2 $\mathrm{ANP}^{-/-}$mice (B); Plasma cGMP concentrations (pmol/mL) in male, female OVXVEH and female OVX-E2 $\mathrm{ANP}^{+/+}$mice (C) and in male, female OVX-VEH and female OVX-E2 ANP ${ }^{-/-}$mice (D); Data are presented as means \pm S.E.M. ${ }^{*} \mathrm{P} \leq 0.05$, using one-way ANOVA and Tukey's post hoc test. $\mathrm{N}=3$ - 6 .

physiological and pathological changes to the myocardium, and should be a primary consideration in the development of more effective therapeutics to treat CVD [13]. Furthermore, the significant increase in CVD related morbidity and mortality in post-menopausal females supports the role of sex as a cardiovascular system modifier, confirming the need for a targeted sex-specific approach to CVD treatment [14].

It is well recognized that sex hormones contribute to the sex dimorphism in the incidence and development of cardiovascular risk factors and that sex hormone depletion associated with the menopause can have an unfavourable effect on the development of traditionally defined CVD risk factors [15]. The prevailing concern of the increased incidence of cardiovascular risk associated with HRT has long cast suspicion on the beneficial effects of sex hormones [16]. However, recent review and analysis of data retrieved from HRT studies and trials reveals that in certain circumstances, taking into account the mode of delivery, dosage, therapy regime, and time between onset of menopause and HRT commencement, HRT can in fact minimize cardiovascular risk factors [17]. This continuing discrepancy in current opinions on the delicate balance between the risks and benefits of HRT only confirms that our knowledge and understanding of sex hormone signaling and cardioprotective func- tion remain incomplete.

This current study served multiple purposes: 1) to add to our understanding of how sex hormones confer their cardioprotective effect through modulation of cardiac gene systems that impact cardiac remodeling mechanisms; 2) to further elucidate and confirm if the estrous cycle changes associated with changes in cardiac gene system expression that we observed previously are indeed attributable to sex hormones, namely estrogen; and 3) to underline and support the idea that males and females are inherently different, and that each sex should be considered and thus treated as such.

The development of $\mathrm{CH}$ is considered a primary risk factor for CVD as these abnormal compensatory cellular adaptations, as a consequence of pathological stimuli such as chronically elevated hemodynamic demands and adverse biomechanical stresses, can ultimately lead to arrhythmia, heart failure and death [18]. The effect of estrogen on the modulation of cardiac gene systems, primarily through estrogen receptor $\beta$, affects the development of the $\mathrm{CH}$ response and is thought to contribute to its cardioprotective function in women [19-22]. The cardiac NP and NOS systems modulate the $\mathrm{CH}$ response and are able to be activated by systemic estrogen. E2 has been found to attenuate the development of pressureoverload hypertrophy induced by transverse aortic con- 
striction (TAC) and has been linked to an upregulation in ANP expression [23]. This E2-induced activation of ANP was further confirmed in the rat heart [24]. Sangaralingham et al. also demonstrated the involvement of the NP system in E2-mediated protection from salt-induced cardiac hypertrophy in heterozygous pro-ANP genedisrupted $\left(\mathrm{ANP}^{-/}\right)$mice [12]. In addition, E2 has been found to stimulate components of the NOS system, iNOS and eNOS, in the myocardium as evidenced from assessment of the effect of E2 on neonatal and adult rat cardiomyocytes [25]. The link between E2 and downstream eNOS signaling was confirmed in a study that showed that OVX-mediated augmentation of pressure overload hypertrophy caused resultant changes in Akt and NOS signaling pathways [26]. Further investigation into the impact of pressure overload and E2 signaling has revealed that iNOS activity is mediated primarily by response to pressure overload and eNOS activity is mediated by E2 signaling [27].

Enlisting the use of the $\mathrm{ANP}^{-/-}$mouse model, the interrelation between the NP and NOS systems and their subsequent impact on downstream cGMP was further delineated previously, confirming the existence of sexspecific differences in the expression of these two systems, as well as an additional level of estrous cycle-mediated regulation of the NOS system [8]. However tempting it is to directly attribute these gene expression changes to sex hormones, it is important to note that the estrous cycle is a physical manifestation of multiple, complex signaling mechanisms, and sex hormones only play a part. Thus, this study sought to confirm if in fact these observed estrous cycle-mediated cardiac gene expression changes were indeed attributable to estrogen.

Ovariectomy (OVX) and subsequent reintroduction of $\mathrm{E} 2$ into female $\mathrm{ANP}^{+/+}$and $\mathrm{ANP}^{-/-}$mice served multiple purposes: firstly, removal of the ovaries permitted assessment of potential sex-specific, ovary-independent factors that may contribute to sex dimorphic expression of cardiac gene systems when comparing male $\mathrm{ANP}^{+/+}$ and $\mathrm{ANP}^{-/-}$mice age-matched with female OVX-VEH $\mathrm{ANP}^{+/+}$and $\mathrm{ANP}^{-/-}$mice. Secondly, reintroduction of E2 in the female $\mathrm{ANP}^{+/+}$and $\mathrm{ANP}^{-/}$OVX-E2 treatment groups permitted demonstration of the sole effects of E2 on the expression of cardiac gene systems. This study sought to confirm how E2 signaling is facilitated in tandem through these two converging pathways, independent of other ovary specific factors and sex hormones, an opportunity conveniently permitted by the $\mathrm{ANP}^{-/-}$mouse model.

The $\mathrm{ANP}^{--}$mice are chronically hypertensive and possess significant cardiac hypertrophy compared to its wild type counterpart. As expected male, female OVX$\mathrm{VEH}$ and female OVX-E2 $\mathrm{ANP}^{-/-}$mouse treatment groups exhibited significant cardiac hypertrophy com- pared to their respective $\mathrm{ANP}^{+/+}$treatment groups. Treatment with E2 did not impact the extent of cardiac hypertrophy compared with vehicle treated groups in each respective genotype.

Analysis of expression of the NP system components, ANP, BNP, NPR-A and NPR-C was accomplished by qPCR. There was no significant difference in the expression of these genes across genotype, sex and E2 treatment. Expression of ANP was slightly elevated in male $\mathrm{ANP}^{+/+}$mice compared with female OVX-VEH and OVX-E2 $\mathrm{ANP}^{+/+}$mice, a pattern that was found previously when comparing ANP expression in male $\mathrm{ANP}^{+/+}$ mice compared with female $\mathrm{ANP}^{+/+}$mice with intact ovaries in proestrus [8]. The absence of changes in the NP system despite OVX and reintroduction of E2 was surprising but not wholly unexpected. The wealth of studies designating the NP system as a downstream target of E2, often enlist transverse aortic constriction (TAC) or other stressful means of procuring a pressure-overload hypertrophy in animal models [28-30]. The finding that reintroduction of E2 in OVX female mice, regardless of genotype, does not alter expression of NP system components confirms that although E2 is capable of enlisting the NP system, it only does so in instances of significant pathological insult and stress in order to contribute to the upregulation of downstream cGMP.

Interestingly, it was the expression of NOS system components, iNOS, eNOS, sGC $\alpha_{1}$ and $\mathrm{sGC} \beta_{1}$ that demonstrated and confirmed sex-specific differences as well as the overriding regulation by E2. Levels of eNOS were significantly elevated in female OVX-VEH $\mathrm{ANP}^{+/+}$mice compared with male $\mathrm{ANP}^{+/+}$mice. As well, levels of both iNOS and eNOS were significantly elevated in female OVX-VEH $\mathrm{ANP}^{-/-}$mice compared with male $\mathrm{ANP}^{-/-}$ mice. This finding is significant because it provides clear indication that the presence of sex hormones in females with intact ovaries cannot alone account for the sex-specific differences in cardiac gene expression. Even despite removal of the ovaries, a surgical intervention that should in theory render females as phenotypic males, there is something ovary-independent and intrinsically female that contributes to the significantly higher levels of iNOS and eNOS in females compared to males. This observation of ovary independent sex-specific differences is similar to one made by O'Connell et al.; they noted that ovariectomy of females did not ablate the sex-specific differences observed in the function of $\alpha_{1}$-adrenergic receptors and their impact on heart size and response to pathological and physiological stimuli [31].

Analysis of the NOS system gene expression revealed an overarching trend towards increased expression of NOS system components in female OVX-VEH $\mathrm{ANP}^{+/+}$ and $\mathrm{ANP}^{-/}$mice compared to their respective male genotype counterparts. Furthermore, reintroduction of E2 
in female OVX-E2 $\mathrm{ANP}^{+/+}$and $\mathrm{ANP}^{-/-}$mice resulted in a trend towards even higher NOS system component gene expression compared to both OVX-E2 and male $\mathrm{ANP}^{+/+}$ and $\mathrm{ANP}^{-/-}$mice. Expression of iNOS in female OVX$\mathrm{E} 2 \mathrm{ANP}^{-/}$mice was significantly higher compared to male $\mathrm{ANP}^{-/-}$mice. In both $\mathrm{ANP}^{+/+}$and $\mathrm{ANP}^{-/-}$mice, levels of eNOS, sGC $\alpha_{1}$ and $\mathrm{sGC} \beta_{1}$ were significantly elevated in female OVX-E2 mice compared with male mice. These findings demonstrate that the presence of E2 further augments the sex-specific differences observed in the expression of the cardiac NOS system. The significantly decreased level of iNOS in female OVX-E2 $\mathrm{ANP}^{+/+}$mice compared to female OVX-VEH $\mathrm{ANP}^{+/+}$ mice is somewhat surprising. The classic understanding of E2 signaling involves the concurrent increase in iNOS and eNOS to facilitate downstream upregulation of cGMP production [25]. However, it has been noted that in some instances, including angiotensin II-based stimulation of endothelial cells, E2 can effectively downregulate the expression of iNOS and eNOS [32]. One can also speculate that in a situation of minimal stress, where signaling through eNOS via E2 is sufficient and not requiring recruitment of a significant amount of iNOS could explain the lower levels of iNOS in female OVX-E2 $\mathrm{ANP}^{-/}$mice compared with female OVX-VEH $\mathrm{ANP}^{-/}$ mice. Regardless, these results show that the NOS system is a key system that is activated by E2, and demonstrates the sex dimorphic expression of cardiac genes; E2-mediated signaling through the NOS system may very well contribute to cardioprotective modulation of the cardiac remodeling response.

As stated previously, both the NP and NOS systems converge on the downstream production of secondary messenger cGMP. Further signaling initiated by cGMP acts on protein kinase $\mathrm{G}$, which itself acts to inhibit cardiac hypertrophic signaling systems including the calcineurin-NFAT and CaM kinase signaling pathways [33, 34]. For both $\mathrm{ANP}^{+/+}$and $\mathrm{ANP}^{-/-}$mice, left ventricle tissue cGMP levels remained unchanged across sex, OVX and E2 treatment. This was expected due to the tight regulation of tissue cGMP levels; excess cGMP is immediately released into the systemic circulation or degraded by local phosphodiesterases [35]. Plasma cGMP levels in $\mathrm{ANP}^{+/+}$mice remained unchanged across sex, OVX and $\mathrm{E} 2$ treatment. In $\mathrm{ANP}^{-/-}$mice, there was no change in plasma cGMP when comparing male and female OVX$\mathrm{VEH}$. However, there was a significant increase in plasma cGMP in the female OVX-E2 $\mathrm{ANP}^{-/-}$mice compared to male and female OVX-VEH $\mathrm{ANP}^{-/-}$mice. This shows that in the absence of the ANP signaling, E2 enlists the use of the NOS system, likely eNOS primarily, to upregulate cGMP. In the instance of the $\mathrm{ANP}^{+/+}$mice treatment groups, since the ANP signaling axis remains intact, both NP and NOS systems are working together to conserve the downstream levels of cGMP.

The results of this study further support and confirm the understanding that males and females are inherently different and as such, must ultimately be considered and treated differently. As shown, sex dimorphic expression of specific cardiac gene systems is attributable to the presence of sex hormones. Our findings indicate that in normal circumstances, E2 acts on both the NP and NOS systems to conserve downstream cGMP. However, in the absence of the ANP signaling axis in the $\mathrm{ANP}^{-/-}$mouse, E2 primarily activates the cardiac NOS system, which in turn contributes to the significantly elevated systemic plasma cGMP. Based on these findings of E2-mediated activation of the cardiac NOS gene system, it can be concluded that this particular system is an important contributor to the modulation of the $\mathrm{CH}$ response and the sex-specific cardioprotection observed in women. By extension, we speculate that this particular system may be a promising target for the future development of sex-specific treatments for CVD.

\section{Acknowledgements}

PGW is a recipient of the R.J. Wilson Graduate Award and Ontario Graduate Scholarship Award. DWJA is a recipient of an Ontario Graduate Scholarship Award. Financial support from the Heart and Stroke Foundation of Ontario to SCP (Grant \#: NA7297) is gratefully acknowledged. The purchase of the Roche Lightcycler 480II was made possible by a Canada Foundation for Innovation (CFI) equipment grant to Drs. Amsden, Waldman and Pang.

\section{REFERENCES}

[1] A. S. Go, D. Mozaffarian, V. L. Roger, E. J. Benjamin, J. D. Berry, W. B. Borden, D. M. Bravata, S. Dai, E. S. Ford, C. S. Fox, S. Franco, H. J. Fullerton, C. Gillespie, S. M. Hailpern, J. A. Heit, V. J. Howard, M. D. Huffman, B. M. Kissela, S. J. Kittner, D. T. Lackland, J. H. Lichtman, L. D. Lisabeth, D. Magid, G. M. Marcus, A. Marelli, D. B. Matchar, D. K. McGuire, E. R. Mohler, C. S. Moy, M. E. Mussolino, G. Nichol, N. P. Paynter, P. J. Schreiner, P. D. Sorlie, J. Stein, T. N. Turan, S. S. Virani, N. D. Wong, D. Woo, M. B. Turner, on Behalf of the American Heart Association Statistics Committee and Stroke Statistics Subcommittee, "Executive Summary: Heart Disease and Stroke Statistics: 2013 Update: A Report from the American Heart Association," Circulation, Vol. 127, No. 1, 2013, pp. 143-152. doi:10.1161/CIR.0b013e318282ab8f

[2] J. Johannes and C. N. Bairey Merz, "Is Cardiovascular Disease in Women Inevitable?" Cardiology in Review, Vol. 19, No. 2, 2011, pp. 76-80. doi:10.1097/CRD.0b013e318209a711

[3] W. S. Post, M. G. Larson, and D. Levy, "Impact of Left Ventricular Structure on the Incidence of Hypertension. The Framingham Heart Study," Circulation, Vol. 90, No. 
1, 1994, pp. 179-185. doi:10.1161/01.CIR.90.1.179

[4] N. Frey and E. N. Olson, "Cardiac Hypertrophy: The Good, the Bad, and the Ugly," Annual Review of Physiology, Vol. 65, No. 1, 2003, pp. 45-79. doi:10.1146/annurev.physiol.65.092101.142243

[5] R. Feil, S. M. Lohmann, H. de Jonge, U. Walter and F. Hofmann, "Cyclic GMP-Dependent Protein Kinases and the Cardiovascular System: Insights from Genetically Modified Mice," Circulation Research, Vol. 93, No. 10, 2003, pp. 907-916. doi:10.1161/01.RES.0000100390.68771.CC

[6] T. Nishikimi, N. Maeda and H. Matsuoka, "The Role of Natriuretic Peptides in Cardioprotection," Cardiovascular Research, Vol. 69, No. 2, 2006, pp. 318-328. doi:10.1016/j.cardiores.2005.10.001

[7] J. Hammond and J.-L. Balligand, "Nitric Oxide Synthase and Cyclic GMP Signaling in Cardiac Myocytes: From Contractility to Remodeling," Journal of Molecular and Cellular Cardiology, Vol. 52, No. 2, 2012, pp. 330-340. doi:10.1016/j.yjmcc.2011.07.029

[8] P. G. Wong, D. W. J. Armstrong, M. Y. Tse, E. P. A. Brander and S. C. Pang, "Sex-Specific Differences in Natriuretic Peptide and Nitric Oxide Synthase Expression in ANP Gene-Disrupted Mice," Molecular and Cellular Biochemistry, Vol. 374, No. 1, 2012, pp. 125-135. doi:10.1007/s11010-012-1511-8

[9] E. Barrett-Connor and D. Grady, "Hormone Replacement Therapy, Heart Disease, and Other Considerations," Annual Review of Public Health, Vol. 19, 1998, pp. 55-72. doi:10.1146/annurev.publhealth.19.1.55

[10] E. Angelis, M. Y. Tse and S. C. Pang, "Interactions between Atrial Natriuretic Peptide and the Renin-Angiotensin System during Salt-Sensitivity Exhibited by the proANp Gene-Disrupted Mouse," Molecular and Cellular Biochemistry, Vol. 276, No. 1, 2005, pp. 121-131. doi:10.1007/s11010-005-3672-1

[11] S. J. Sangaralingham, M. Y. Tse and S. C. Pang, "Estrogen Delays the Progression of Salt-Induced Cardiac Hypertrophy by Influencing the Renin-Angiotensin System in Heterozygous proANP Gene-Disrupted Mice," Molecular and Cellular Biochemistry, Vol. 306, No. 1, 2007, pp. 221-230. doi:10.1007/s11010-007-9573-8

[12] S. J. Sangaralingham, M. Y. Tse and S. C. Pang, "Estrogen Protects against the Development of Salt-Induced Cardiac Hypertrophy in Heterozygous proANP GeneDisrupted Mice," Journal of Endocrinology, Vol. 194, No. 1, 2007, pp. 143-152. doi:10.1677/JOE-07-0130

[13] L. A. Leinwand, "Sex Is a Potent Modifier of the Cardiovascular System," Journal of Clinical Investigation, Vol. 112, No. 3, 2003, pp. 302-307. doi:10.1172/JCI19429

[14] C. Vassalle, T. Simoncini, P. Chedraui and F. R. PérezLópez, "Why Sex Matters: The Biological Mechanisms of Cardiovascular Disease," Gynecological Endocrinology, Vol. 28, No. 9, 2012, pp. 746-751. doi:10.3109/09513590.2011.652720

[15] G. M. C. Rosano, C. Vitale, G. Marazzi and M. Volterrani, "Menopause and Cardiovascular Disease: The Evidence," Climacteric, Vol. 10, No. 1, 2007, pp. 19-24. doi:10.1080/13697130601114917
[16] W. B. Kannel, M. C. Hjortland, P. M. McNamara and T. Gordon, "Menopause and Risk of Cardiovascular Disease: The Framingham Study," Annals of Internal Medicine, Vol. 85, No. 4, 1976, pp. 447-452. doi:10.7326/0003-4819-85-4-447

[17] S. R. Salpeter, J. M. E. Walsh, T. M. Ormiston, E. Greyber, N. S. Buckley and E. E. Salpeter, "Meta-Analysis: Effect of Hormone-Replacement Therapy on Components of the Metabolic Syndrome in Postmenopausal Women," Diabetes Obesity \& Metabolism, Vol. 8, No. 5, 2006, pp. 538-554. doi:10.1111/i.1463-1326.2005.00545.x

[18] J. Heineke and J. D. Molkentin, "Regulation of Cardiac Hypertrophy by Intracellular Signalling Pathways," $\mathrm{Na}$ ture Reviews Molecular Cell Biology, Vol. 7, No. 8, 2006, pp. 589-600. doi:10.1038/nrm1983

[19] M. Skavdahl, C. Steenbergen, J. Clark, P. Myers, T. Demianenko, L. Mao, H. A. Rockman, K. S. Korach and E. Murphy, "Estrogen Receptor- $\beta$ Mediates Male-Female Differences in the Development of Pressure Overload Hypertrophy," American Journal of Physiology: Heart and Circulatory Physiology, Vol. 288, No. 2, 2004, pp. H469H476. doi:10.1152/ajpheart.00723.2004

[20] F. A. Babiker, D. Lips, R. Meyer, E. Delvaux, P. Zandberg, B. Janssen, G. van Eys, C. Grohé and P. A. Doevendans, "Estrogen Receptor $\beta$ Protects the Murine Heart Against Left Ventricular Hypertrophy," Arteriosclerosis Thrombosis and Vascular Biology, Vol. 26, No. 7, 2006, pp. 1524-1530. doi:10.1161/01.ATV.0000223344.11128.23

[21] A. Pedram, M. Razandi, M. Aitkenhead and E. R. Levin, "Estrogen Inhibits Cardiomyocyte Hypertrophy in Vitro: Antagonism of Calcineurin-Related Hypertrophy through Induction of MCIP1," Journal of Biological Chemistry, Vol. 280, No. 28, 2005, pp. 26339-26348. doi:10.1074/jbc.M414409200

[22] A. Pedram, M. Razandi, D. Lubahn, J. Liu, M. Vannan and E. R. Levin, "Estrogen Inhibits Cardiac Hypertrophy: Role of Estrogen Receptor- $\beta$ to Inhibit Calcineurin," Endocrinology, Vol. 149, No. 7, 2008, pp. 3361-3369. doi:10.1210/en.2008-0133

[23] M. van Eickels, C. Grohé, J. P. M. Cleutjens, B. J. Janssen, H. J. J. Wellens and P. A. Doevendans, "17 $\beta$-Estradiol Attenuates the Development of Pressure-Overload Hypertrophy," Circulation, Vol. 104, No. 12, 2001, pp. 1419-1423. doi:10.1161/hc3601.095577

[24] M. Jankowski, G. Rachelska, W. Donghao, S. M. McCann and J. Gutkowska, "Estrogen Receptors Activate Atrial Natriuretic Peptide in the Rat Heart," Proceedings of the National Academy of Sciences USA, Vol. 98, No. 20, 2001, pp. 11765-11770. doi:10.1073/pnas.201394198

[25] S. Nuedling, S. Kahlert, K. Loebbert, P. A. Doevendans, R. Meyer, H. Vetter and C. Grohé, "17 Beta-Estradiol Stimulates Expression of Endothelial and Inducible NO Synthase in Rat Myocardium In-Vitro and In-Vivo," Cardiovascular Research, Vol. 43, No. 3, 1999, pp. 666-674. doi:10.1016/S0008-6363(99)00093-0

[26] M. S. Bhuiyan, N. Shioda and K. Fukunaga, "Ovariectomy Augments Pressure Overload-Induced Hypertrophy Associated with Changes in Akt and Nitric Oxide Syn- 
thase Signaling Pathways in Female Rats," American Journal of Physiology: Endocrinology and Metabolism, Vol. 293, No. 6, 2007, pp. E1606-E1614. doi:10.1152/ajpendo.00246.2007

[27] X. Loyer, T. Damy, Z. Chvojkova, E. Robidel, F. Marotte, P. Oliviero, C. Heymes and J. L. Samuel, "17 $\beta$-Estradiol Regulates Constitutive Nitric Oxide Synthase Expression Differentially in the Myocardium in Response to Pressure Overload," Endocrinology, Vol. 148, No. 10, 2007, pp. 4579-4584. doi:10.1210/en.2007-0228

[28] R. D. Patten, I. Pourati, M. J. Aronovitz, A. Alsheikh-Ali, S. Eder, T. Force, M. E. Mendelsohn and R. H. Karas, "17 Beta-Estradiol Differentially Affects Left Ventricular and Cardiomyocyte Hypertrophy Following Myocardial Infarction and Pressure Overload," Journal of Cardiac Failure, Vol. 14, No. 3, 2008, pp. 245-253. doi:10.1016/j.cardfail.2007.10.024

[29] H. Witt, C. Schubert, J. Jaekel, D. Fliegner, A. Penkalla, K. Tiemann, J. Stypmann, S. Roepcke, S. Brokat, S. Mahmoodzadeh, E. Brozova, M. M. Davidson, P. Ruiz Noppinger, C. Grohé and V. Regitz-Zagrosek, "Sex-Specific Pathways in Early Cardiac Response to Pressure Overload in Mice," Journal of Molecular Medicine, Vol. 86, No. 9, 2008, pp. 1013-1024. doi:10.1007/s00109-008-0385-4

[30] X.-M. Li, Y.-T. Ma, Y.-N. Yang, F. Liu, B.-D. Chen, W. Han, J.-F. Zhang and X.-M. Gao, "Downregulation of Survival Signalling Pathways and Increased Apoptosis in the Transition of Pressure Overload-Induced Cardiac Hypertrophy to Heart Failure," Clinical and Experimental Pharmacology and Physiology, Vol. 36, No. 11, 2009, pp. 1054-1061. doi:10.1111/j.1440-1681.2009.05243.x
[31] T. D. O’Connell, S. Ishizaka, A. Nakamura, P. M. Swigart, M. C. Rodrigo, G. L. Simpson, S. Cotecchia, D. G. Rokosh, W. Grossman, E. Foster and P. C. Simpson, "The $\alpha 1 \mathrm{~A} / \mathrm{C}$ - and $\alpha 1 \mathrm{~B}$-Adrenergic Receptors Are Required for Physiological Cardiac Hypertrophy in the Double-Knockout Mouse," Journal of Clinical Investigation, Vol. 111, No. 11, 2003, pp. 1783-1791. doi:10.1172/JCI16100

[32] F. S. Gragasin, Y. Xu, I. A. Arenas, N. Kainth and S. T. Davidge, "Estrogen Reduces Angiotensin II-Induced Nitric Oxide Synthase and NAD(P)H Oxidase Expression in Endothelial Cells," Arteriosclerosis Thrombosis and Vascular Biology, Vol. 23, No. 1, 2002, pp. 38-44. doi:10.1161/01.ATV.0000047868.93732.B7

[33] J. D. Molkentin, J. R. Lu, C. L. Antos, B. Markham, J. Richardson, J. Robbins, S. R. Grant and E. N. Olson, "Acalcineurin-Ependent Transcriptional Pathway for Cardiac Hypertrophy," Cell, Vol. 93, No. 2, 1998, pp. 215228. doi:10.1016/S0092-8674(00)81573-1

[34] R. Passier, H. Zeng, N. Frey, F. J. Naya, R. L. Nicol, T. A. McKinsey, P. Overbeek, J. A. Richardson, S. R. Grant and E. N. Olson, "CaM kinas Signaling Induces Cardiac Hypertrophy and Activates the MEF2 Transcription Factor in Vivo," Journal of Clinical Investigation, Vol. 105, No. 10, 2000, pp. 1395-1406. doi:10.1172/JCI8551

[35] S. D. Rybalkin, C. Yan, K. E. Bornfeldt and J. A. Beavo, "Cyclic GMP Phosphodiesterases and Regulation of Smooth Muscle Function," Circulation Research, Vol. 93, No. 4, 2003, pp. 280-291. doi:10.1161/01.RES.0000087541.15600.2B 